\title{
Inflation: A Malaysia Story
}

\author{
Zetty Ain Kamaruzzaman
}

\begin{abstract}
Inflation in economics is defined as "a persistent and sustained increase in the aggregate or average price level of goods and services in an economy". Inflation is mysterious where it can effect economy in various ways, either positive or negative. Inflation is measured using Consumer Price Index (CPI). Thus, this paper presents the story of inflation from Malaysia point of view. This paper also outlines the basic concept of inflation as its understanding is vital for policy decision-making.
\end{abstract}

Index Terms: consumer price index, deflation, economy, Malaysia, inflation.

\section{INTRODUCTION}

The term "inflation" used by economists is to denote "a persistent and sustained increase in aggregate or average price level of goods and services in an economy" [1]. Inflation plays vital role in every nation. It can also effect economies in various ways. To understand its role and effects to a nation and economy in whole, one must first understand its basic concepts.

Thus, in this paper, the main objective is to present the Malaysia story of inflation. This study will contribute towards a better decision-making, help stakeholders to understand inflation concepts in an easier and more effective way as well as provide a simple insight in analyzing inflation.

This paper is presented as follows. Section 2 summarizes literature review. Next, we outline the methodology. Section 4 presents results and discussion. Lastly, the conclusion.

\section{LITERATURE REVIEW}

\section{A. Inflation}

Inflation is defined as "a persistent and sustained increase in the aggregate or average price level of goods and services in an economy" [1]. When general prices increase, the consumer purchasing power will decrease. Inflation rate is the measure of inflation over time.

In general, inflation is referred as "the cost of living". For example, prices of goods as compared from 20 years ago. Your grandparents may recall, "a movie ticket only cost them RM1.00 20 years ago". They are actually make a comparative observation about inflation, the cost of goods and services over time. We can understand this in two ways, prices rise or the value of money fall.

Inflation implies that there is an increase in the living cost

\footnotetext{
Revised Manuscript Received on September 22, 2019.

Zetty Ain Kamaruzzaman, Faculty of Industrial Management, Universiti Malaysia Pahang, Gambang, Malaysia.
}

which will cause lower purchasing power. It is a situation where there is too much money chasing too few goods. There is an inverse relationship between inflation and value of money. If inflation is high, the money value is low, and vice versa. With inflation, there is a loss of currency value because the consumers' money now will not buy goods as much today as it could yesterday [1].

Inflation is measured using the Consumer Price Index (CPI) data over a period of time (months or years). CPI is also known as the cost of living index. This is because it measures the changes in the average price of consumer goods and services. An increase in this cost is called inflation. Meanwhile, a decrease in this cost is called deflation. Therefore, CPI will tell us what has happened to the value of money that we hold.

Consumer Price Index (CPI) measures the changes in the average price of consumer goods and services. Its calculation involves four stages. Table I summarizes each stages.

There are six main types of inflation as categorized by their speed: creeping, walking, running, galloping, hyperinflation and stagflation. Table II summarizes the degree of inflation.

Inflation is classified into three types: demand-pull inflation, cost-push inflation and built-in inflation [2]. Robert J. Gordon classify it as the triangle model [3]. Table III summarizes the types and causes of each inflation.

Inflation can be good and bad, depending upon which side one takes. It affects economies in various positive and negative ways. The negative effect is the increase in the opportunity cost of holding money. On the other hand, positive effect is the reduction in unemployment. The seriousness of the adverse effects depends on whether inflation is anticipated or unanticipated [1]. Anticipated inflation is when people are more or less prepared for the inflation. On contrary, unanticipated inflation is when inflation comes as a surprise to the public or comes before the people had time to fully adjust on its presence.

Contractionary fiscal policy, contractionary monetary policy and direct control can be used to control inflation [1]. The choice of policies type to control inflation depends on its causes. In late 20th century, there is a debate between Keynesians and monetarists on how to control inflation. In the 21 st century, most economists favor a low and steady rate of inflation [2].

Inflation causes the redistribution of income or wealth and breakdown in the functions of money. Thus, inflation needs to be controlled, because the spike in inflation indicates that the demand is rising too fast. This is what being explained by too much money chasing too few goods. 


\section{B. Definition of Key Terms}

Table IV summarizes the main key terms of economic concepts related to inflation.

Table I. Stages to calculate Consumer Price Index (CPI) [1]

\begin{tabular}{|c|c|}
\hline Stage & Description \\
\hline $\begin{array}{l}\text { 1. Select a base year } \\
\text { that everything gets } \\
\text { compared to }\end{array}$ & $\begin{array}{l}\text { The base year is the reference base year. It acts as a benchmark against the compared years. The } \\
\text { CPI for base year is defined to equal to } 100 \text {. The base year must be a normal year where the } \\
\text { economy and prices are stable. }\end{array}$ \\
\hline $\begin{array}{l}\text { 2. Select the CPI } \\
\text { basket of goods and } \\
\text { services }\end{array}$ & $\begin{array}{l}\text { A representative fixed basket of typical consumption of goods and services of a general } \\
\text { household such as foods, shelter, clothing, medical, furniture and transportation will be selected } \\
\text { to construct CPI. This basket of goods is viewed every year by adding or removing some items in } \\
\text { the basket. This is done: (i) to reflect the changes in the market; (ii) to ensure that the indices are } \\
\text { up to date; (iii) to represent consumer spending pattern. }\end{array}$ \\
\hline $\begin{array}{l}\text { 3. Conduct a } \\
\text { monthly prices of } \\
\text { selected goods }\end{array}$ & A prices survey of selected goods will be conducted from reliable sources. \\
\hline $\begin{array}{l}\text { 4. Give weightage of } \\
\text { relative importance } \\
\text { for each category of } \\
\text { goods and services }\end{array}$ & $\begin{array}{l}\text { Weightage is used to measure the relative importance of the items in the CPI baskets. This } \\
\text { depends on the amount of money spent by consumer. The highest weightage shows the most } \\
\text { important commodity for the consumer, and vice versa. A weighted CPI measures the changes in } \\
\text { the average prices of a market basket of goods and services purchased by a typical urban } \\
\text { household by taking into account the importance of certain goods and services relative to the } \\
\text { others. }\end{array}$ \\
\hline
\end{tabular}

Table II. Degree of inflation [1]

\begin{tabular}{|c|c|}
\hline Types & Description \\
\hline Creeping & The mildest form of inflation. \\
\hline Walking & Known as trotting inflation. The rising price rate is more than creeping inflation. \\
\hline Running & Rapid rate of rising prices. \\
\hline Galloping & $\begin{array}{l}\text { Known as jumping inflation. Money becomes valueless. This is a very serious } \\
\text { economic condition. }\end{array}$ \\
\hline Hyperinflation & Value of money reduces to almost zero. \\
\hline $\begin{array}{l}\text { Stagflation / } \\
\text { Slumpflation }\end{array}$ & $\begin{array}{l}\text { High rates of inflation combined with high unemployment and stagnant economic } \\
\text { growth. }\end{array}$ \\
\hline \multicolumn{2}{|r|}{ Table III. Types and causes of inflation [2] } \\
\hline Types & Causes \\
\hline Demand-pull & $\begin{array}{l}\text { Caused by an increases in aggregate demand. This may be due to increase of private and } \\
\text { government spending. }\end{array}$ \\
\hline Cost-push & $\begin{array}{l}\text { Caused by a drop in aggregate supply or potential output. This may be due to the natural } \\
\text { disasters or increased in input prices. }\end{array}$ \\
\hline Built-in & $\begin{array}{l}\text { Caused by adaptive expectations. It is due to the price or wage spiral. It involves workers } \\
\text { who try to keep their wages up with prices (above the rate of inflation), firms then pass the } \\
\text { higher labor costs onto their customers through higher prices. It leads to a vicious circle. It } \\
\text { also reflects events in the past, thus, known as hangover inflation. }\end{array}$ \\
\hline
\end{tabular}


Table IV. Definition of key terms [1-2]

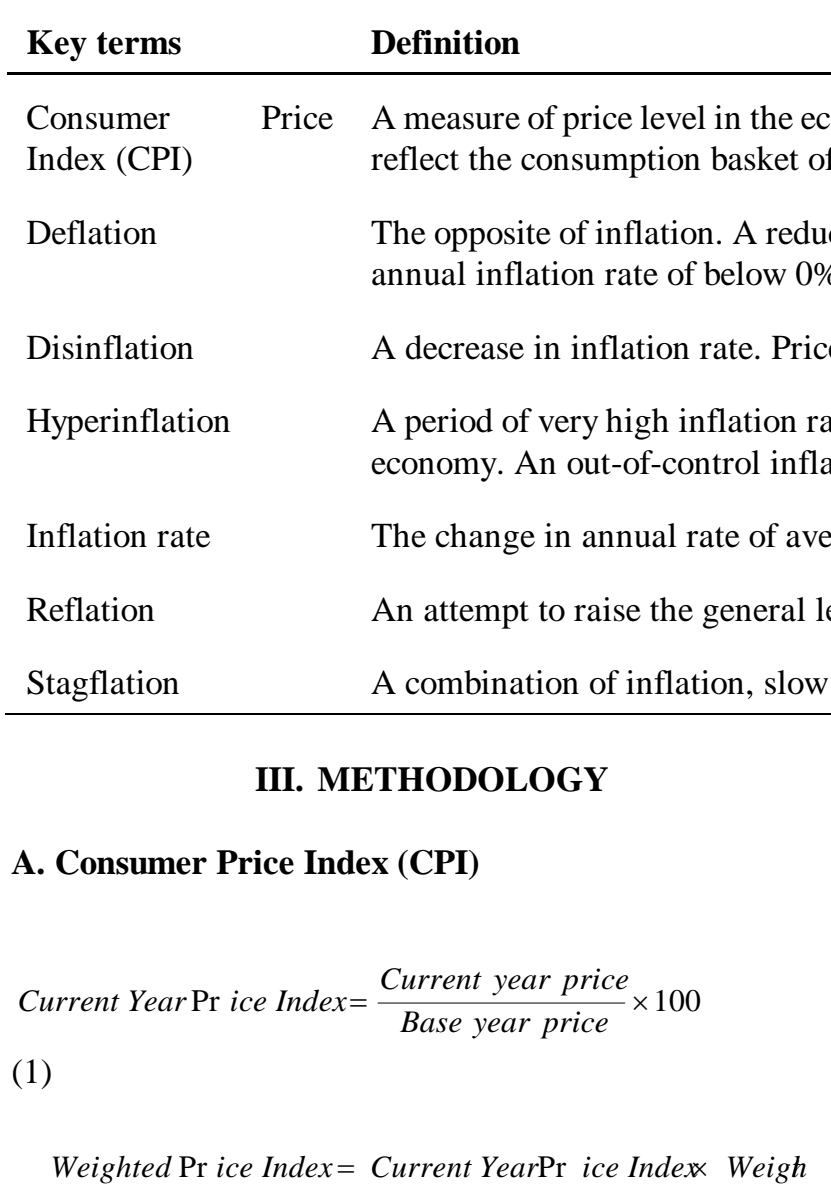

Overall Weighted CPI $=\frac{\sum \text { Weighted price index }}{\text { Total weights }}$

\section{B. Inflation}

Inflation $=\frac{\text { CPI current year }- \text { CPI previous year }}{C P I \text { previous year }} \times 100 \%$

$\operatorname{Re}$ al Value of Money $=\frac{\text { Base year index }}{\text { Current year CPI }} \times 100 \%$

Change in Value of Money $=\left[\frac{\text { Base year index }}{\text { Current year CPI }}-1\right] \times 100 \%$

(6)

\section{RESULTS AND DISCUSSION}

In this paper, we present the Malaysia story of inflation.

\section{A. Malaysia Story of Inflation}

Malaysia inflation rate averaged 3.55 percent from 1973 until 2019. The inflation rate reached the all-time high of 23.90 percent in March 1974. While, the lowest record stated is -2.40 percent in July 2009 [4].

Fig. 1 depicts the Malaysia inflation rate from May 2018 April 2019 [4-5]. From Fig. 1, Malaysia consumer price inflation is 0.2 percent year-on-year in April 2019. This figure is the same as the previous month (March 2019).

Malaysia economy has been in deflation mode since January this year. This is the first time since the global financial crisis of 2009. It is due to the drop in fuel price. Prior to this, from June to November 2009, Malaysia have experienced deflation too. The deflation mode continued in two consecutive months until February 2019. The negative inflation for these first two months in year 2019 is a concern. Both the forces of cost-push and demand-pull are in effect causing negative inflation rates [6].

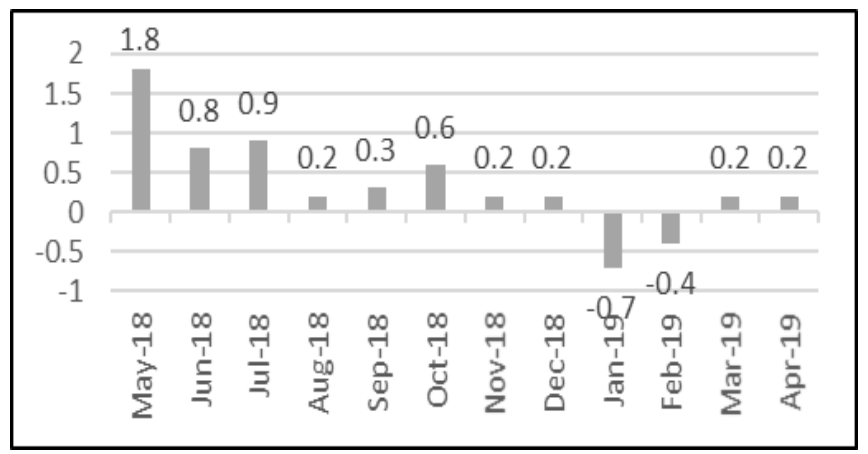

Fig. 1. Malaysia Inflation Rate [4-5]

Fig. 2 depicts the Malaysia consumer price index in April 2019. From Fig. 2, Consumer Price Index (CPI) rise by 0.2 percent in April 2019 to 121.1 as compared to 120.9 in the same month of the preceding year (April 2018).

From Fig. 2, the main groups that contributed to the increases were housing, water, electricity, gas \& other fuels (+2.0 percent), alcoholic beverages \& tobacco $(+1.2$ percent), education $(+1.2$ percent $)$, food \& non-alcoholic beverages $(+1.1$ percent $)$, restaurants $\&$ hotels $(+0.8$ percent $)$ and furnishings, household equipment $\&$ routine household maintenance $(+0.2$ percent).

Other groups show a decrease in Consumer Price Index (CPI) as compared from April 2018. The groups are health (-0.3 percent), recreation services \& culture $(-0.4$ 
percent), communication (-1.1 percent), miscellaneous goods \& services ( -2.0 percent), transport ( -2.6 percent) and clothing and footwear (-3.2 percent).

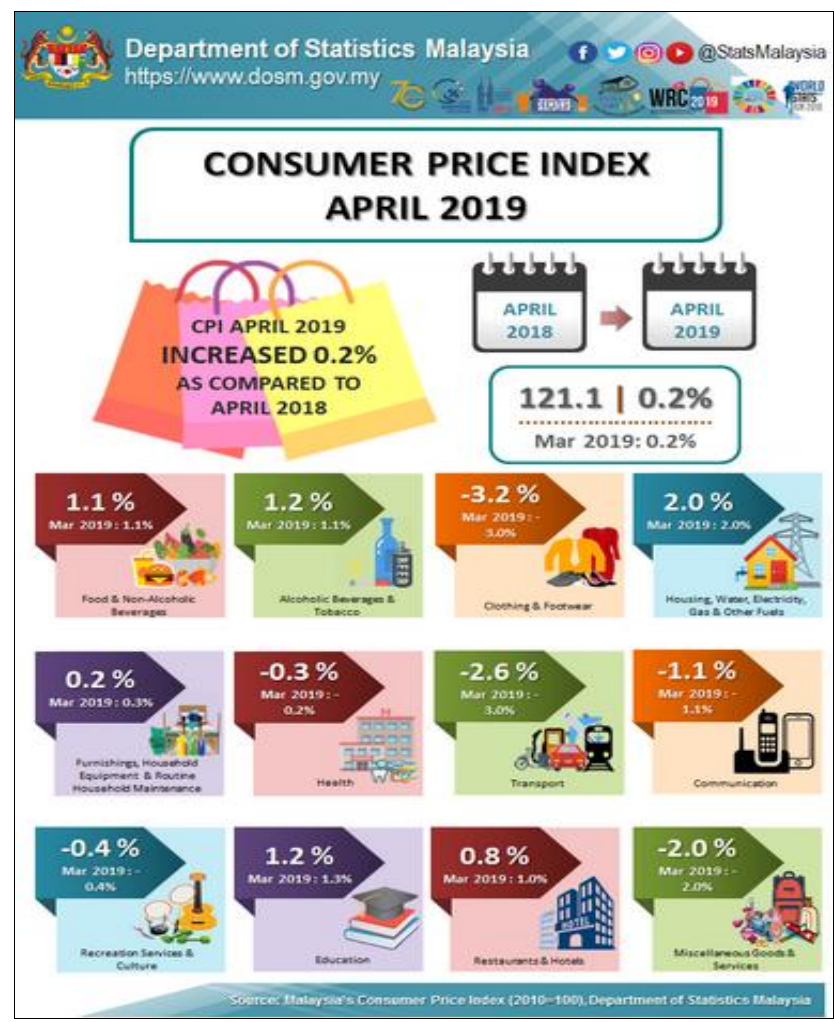

Fig. 2. Malaysia Consumer Price Index April 2019 [4]

Table V summarizes the Malaysia market basket of goods and services with base year Consumer Price Index (CPI) of $2010(2010=100)$. There are 12 main groups.

From Table V, the highest weightage (29.5), food and non-alcoholic beverages shows it the most important commodity to Malaysia consumer. This is followed by housing, water, electricity, gas \& other fuels, where the weightage is 23.8 . Health shows a less important commodity indicator as the weightage is 1.9. The least important commodity to Malaysia consumer is education (weightage $=$ $1.3)$

\section{CONCLUSION}

As a summary, this paper presents the Malaysia story of inflation. This study will contribute towards a better decision- making, help stakeholders to understand inflation concepts in an easier and more effective way as well as provide a simple insight in analyzing inflation.

\section{ACKNOWLEDGMENT}

The author wants to thank anonymous referees whose comments, suggestions and corrections led to a considerably improvement of this paper. Special acknowledgement goes to FIM Computing and Modelling Research Cluster, Faculty of Industrial Management, Universiti Malaysia Pahang.
Table V. Malaysia market basket of goods and services [4]

Main group Weight Index

(April 2019)

\begin{tabular}{|c|}
\hline $\begin{array}{l}\text { Food \& } \\
\text { non-alcoholic } \\
\text { beverages }\end{array}$ \\
\hline $\begin{array}{l}\text { Alcoholic } \\
\text { beverages \& } \\
\text { tobacco }\end{array}$ \\
\hline $\begin{array}{l}\text { Clothing and } \\
\text { footwear }\end{array}$ \\
\hline $\begin{array}{l}\text { Housing, wate } \\
\text { electricity, gas } \\
\text { other fuels }\end{array}$ \\
\hline $\begin{array}{l}\text { Furnishings, } \\
\text { household } \\
\text { equipment \& } \\
\text { routine } \\
\text { household } \\
\text { maintenance }\end{array}$ \\
\hline
\end{tabular}

Health

122.5

Transport

Communication

4.8

96.0

Recreation

services \&

culture

Education

Restaurants and

hotels

Miscellaneous

6.7

\section{REFERENCES}

1. H.C. Tey, A. Nabila, N. Zulkhairi, M.R. Irlisuhayu, \& A.G. Rosmaiza, Fundamentals of Economics. Oxford Fajar, Selangor, Ch. 14, 2017.

2. Inflation, https://en.wikipedia.org/wiki/Inflation

3. R.J. Gordon, Macroeconomics: Theory and Policy, 2nd ed., McGraw-Hill, Ch. 22.4, 1988.

4. Consumer Price Index Malaysia April 2019. Press Release. Department of Statistics Malaysia. https://www.dosm.gov.my

5. Malaysia Inflation Rate, https://tradingeconomics.com > Malaysia

6. Malaysia Economic Outlook 1Q2019. Malaysian Institute of Economic Research. https://www.mier.org.my/old/outlook/archives/2019_04.html

\section{Authors Profile}

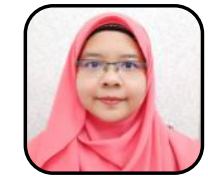

Zetty Ain Kamaruzzaman obtain Doctor of Philosophy (Statistics) from Universiti Kebangsaan Malaysia. Currently, a senior lecturer and Head of FIM Computing \& Modelling Research Cluster at Faculty of Industrial Management, Universiti Malaysia Pahang. 